very considerably according to Thellier's study of Roman bricks ${ }^{2,3}$; and that in consequence the initial activity of radiocarbon, from which the age of a specimen is deduced, must vary too. Atwater and Ellickson challenge the premise that Thellier's measurements are valid ${ }^{4}$. They suggest that incomplete combustion in ancient kilns might cause a reducing atmosphere in which the intensity of magnetization would be greatly increased.

Roman kilns, though usublly simple, were easily controlled, to judge by their products and an experiment undertaken in October 1956 by F. J. Watson, of Wattisfield, Suffolk ${ }^{5}$ Further, many Roman potters took care about the colour of their pots and bricks, and the colour depends partly on the degree of oxidation and reduction in the firing. The frequent 'terra sigillata' (or 'Samian') pottery of the first three centuries A.D. appears to be a completely oxidized ware; at least, refiring in an electric kiln does not make it redder. So measurements of the intensity of the remanent magnetism of 'terra sigillata' should be reliable. It would be interesting to measure and compare the intensity in the common reduced ware of the same period and so to see if reduction as practised by ancient potters had any effect. Dated specimens of Roman oxidized and reduced wares are plentiful.

If the fears of Atwater and Ellickson prove groundless, then it should be possible to determine the magnetic intensity and from it the initial activity of radiocarbon in the past four or five thousand years, provided of course that the only variable factor in forming radiocarbon is the intensity of the magnetic field of the Earth. At many sites from which radiocarbon dates have been obtained there must also be burnt structures or pottery of almost the same date. These are likely to have a remanent magnetization from which the relevant intensity of the Earth's field could be determined. This was probably implied by Elsasser and his colleagues. But there are at least two problems which also must be examined.

First, it may be that the intensity of remanent magnetism decays slightly with time. Reliable observations of changes in the intensity of the Earth's field go back to about 1830 A.D. Bricks and pots made during this period are plentiful, and for some the date of firing (that is, of the acquisition of remanent magnetism) is known to a year or two. By examining such specimens it should be possible to decide whether the intensity of their remanent magnetization has decayed and, if it has, at what sort of rate.

The second problem is whether the influx of cosmic rays also varies. This might be tested on sites which have both radiocarbon specimens and structures or objects possessing remanent magnetization and which also can be dated precisely by historical records or archæological context. On the assumption that the intensity of remanent magnetism gives the initial activity of radiocarbon, the age of the radiocarbon specimen could be calculated: if this date differs from the known date of the site, then it is likely-so far as present theory goes-that the difference is due to a variation in the influx of cosmic rays and this variation could in turn be calculated.

Because of the 'reservoirs' of radiocarbon in the air and sea, small changes in the formation of radiocarbon might not be detectable, but large or sudden changes should be evident, and with enough samples their magnitude might be determined roughly, bus usefully.
I am indebted to Mr. J. C. Belshé and Dr. C. Crowe for directing my attention to the Nature communications and for correcting my terminology.

Museum of Classical Archaeology,

R. M. Соок Cambridge.

'Elsasser, W., Ney, E. P., and Winckler, J. R., Nature, 178, 1226 (1956).

'Thellier, E., C.R. Acad. Sci., Paris, 222, 905 (1946).

${ }^{2}$ Thellier, E., C.R. Acad. Sci., Paris, 212, 281 (1941).

- Atwater, H. A., and Ellickson, R. T., Nature, 181, 404 (1958).

${ }^{5}$ Watson, F. J., Pottery Quarterly (in the press).

\section{Radiation Hazard from Luminous Watches}

IN 1956, the Medical Research Council Committee set up to report on the medical aspects of nuclear radiation estimated that luminous watches and clocks increased the population dose of radiation to the gonads by 1 per cent of the natural background ${ }^{1}$. This estimate was based on the assumption that the average wrist-watch contains about one-fifth of a microcurie of radium. Libby ${ }^{2}$, reporting a similar investigation, quotes a figure of 1 microcurie of radium per watch as being "perhaps slightly larger than average".

I have recently measured the gamma-ray emission from a modern shock-proof self-winding watch, and estimate that it contains $2 \cdot 2$ microcuries of radium. Measurements on eight other watches collected from colleagues revealed contents ranging from 0.01 to 1.2 microcuries with a mean of about one-quarter of a microcurie. Although, therefore, the figure used by the Committee may be substantially correct, there exist watches containing at least ten times this average amount of radium. Should such watches become more popular with the public, then luminous watches would be second only to diagnostic radiology in the amount of radiation they contribute to the gonads.

With larger amounts of radium a hazard might also arise due to irradiation of the skin immediately under the watch. A film placed in contact with the back of the watch containing $2 \cdot 2$ microcuries recorded a dose-rate of 8 milliroentgens per hr. Assuming the watch to be worn $16 \mathrm{hr}$. per day, the skin would therefore receive 0.9 roentgen per week, that is, nearly two-thirds of the present maximum permissible level for exposure to limited parts of the body such as hands and forearms ${ }^{3}$.

The fact that many luminous watches containing one-fifth of a microcurie or less serve their purpose efficiently casts doubt upon the necessity of using much larger quantities. It therefore seems worthwhile to emphasize two of the conclusions drawn by the Committee', namely, that "Adequate justification should be required for the employment of ionizing radiation on however small a scale", and that "The small amounts of irradiation from miscellaneous sources such as X-ray machines used for shoe-fitting, luminous watches and clocks, and television apparatus, should be reduced as far as possible".

Radiotherapeutic Centre, J. L. HAYBitTLe

Addenbrooke's Hospital,

Cambridge.

April 11 .

1 "The Hazards to Man of Nuclear and Allied Radiations" (H.M. Stationery Office, London, 1956).

Libby, W. F., Science, 122, 57 (1955).

Recommendations of the International Commission on Radiologica Protection, Brit. J. Radiol., Supp. No. 6 (1955). 